\title{
Footprint Based Gait Analysis in a Homicide Case - Identified the Culprit as Wife of the Deceased, Also the Complainant: Challenging Forensic Podiatry Crime Scene Report
}

\author{
T. Nataraja Moorthy ${ }^{1 *}$, M. Baskaran ${ }^{2}$
}

${ }^{1}$ Professor of Forensic Sciences, Faculty of Health and Life Sciences, Management and Science University, Shah Alam, Selangor,

Malaysia, Formerly Government Forensic Crime Scene Investigator, Forensic Sciences Department, Home Ministry, Tamilnadu, India ${ }^{2}$ Deputy Commissioner of Police, Police Commissionerate HQ, Madurai City Police, Tamilnadu, India

DOI: $10.36348 /$ sijlcj.2021.v04i03.006

| Received: 22.02.2021 | Accepted: 14.03.2021 | Published: 16.03.2021

*Corresponding author: Prof. T. Nataraja Moorthy

\section{Abstract}

Forensic science works on physical evidence and hence the forensic investigators are searching for physical evidence in the crime scenes to identify the perpetrator and to solve the mystery. The significance of some evidence appears unknown or unimportant at the time of collection from crime scenes but seemingly important as the investigation proceeds. Footprint is an important physical evidence found in many crime scenes such as homicide, burglary and sexual assault, but is simply ignored even in the initial stage of investigation, considering unimportant. Footprint based gait pattern analysis is currently used for person identification. Forensic podiatry is a sub discipline of forensic science in which specialized podiatric knowledge including foot and lower limb, used in the examination of foot-related evidence in the context of a criminal investigation. Footprint and gait analysis are most aligned with other pattern based form of evidence like blood pattern analysis. The gait pattern evidence found mostly in homicide and burglary Crime scenes are also simply neglected by the investigators because of knowledge Lack in podiatry science. The present crime scene report, as investigated by the corresponding author (Prof. T. Nataraja Moorthy, hereafter mention as "TN") in India highlighted the value of footprint and gait pattern evidence in a peculiar homicide crime scene. A woman lodged a complaint with police station in India that her husband was murdered by unknown person but footprint based gait pattern analysis identified the culprit, nobody but the complained wife. She murdered her husband and concealed the fact, a case of "crime concealment".

Keywords: Forensic podiatry, Blood stained foot print. Gait pattern, Homicide, Identification.

Copyright () 2021 The Author(s): This is an open-access article distributed under the terms of the Creative Commons Attribution 4.0 International License (CC BY-NC 4.0) which permits unrestricted use, distribution, and reproduction in any medium for non-commercial use provided the original author and source are credited.

\section{INTRODUCTION}

Forensic science works on physical evidence and hence the forensic investigators are searching for physical evidence in the crime scenes to ink the crime and criminal [1]. Physical evidence may be either a microscopic or a massive item that present at the crime scenes, as silent witness [2]. The physical evidence encountered in the crime scenes are footprint [3], fingerprint [4], hair [5], hand writings [6], soil [7], fiber [8], charred materials $[9,10]$, plastic bags [11] in drug cases and many others. This physical evidence is the link recovering from the crime scenes or from the victims used to solve the mystery. The significance of some evidence appears unknown or unimportant at the time of collection from crime scene but seemingly important as the investigation proceeds. Footprint is an important physical evidence found in many crime scenes such as homicide, burglary and sexual assault, but is simply ignored even in the initial stage of investigation, considering unimportant. Accordingly, the gait pattern evidence found mostly in homicide and burglary are also simply by the investigators. Forensic podiatry is a sub discipline of forensic science in which specialized podiatric knowledge including foot and lower limb anatomy, used in the examination of footrelated evidence in the context of a criminal investigation. Footprint and gait analysis are most aligned with other pattern based form of evidence like blood pattern analysis. The present crime scene report as investigated by the corresponding author (Prof. T. 
T. Nataraja Moorthy\& M. Baskaran., Sch Int J Law Crime Justice, Mar, 2021; 4(3): 166-169

Nataraja Moorthy, hereafter as "TN") in India indicated the value of footprint and gait pattern evidence to arrive a conclusion in a homicide case wherein a wife murdered his husband and lodged a complaint with police stated, that somebody had murdered her husband when she went for work.

\section{Gist of the case}

A village woman in India aged about 40 years old had lodge a complaint in the police station stated that her husband named Chinnakaman, aged about 48 years old found murdered in their house while she returned from work. A case was registered u/s 302 IPC and forensic crime scene investigator was summoned to visit the crime scene and assist the investigation. The forensic crime scene investigator $\mathrm{TN}$ visited the spot and examined the scene of crime.
Examination of the crime scene

On arrival at the crime scene, TN made preliminary enquiries with relatives and neighbours. He then prepared a crime scene sketch as shown in figure 1. It is an indoor crime scene, a small house without any rooms. The entrance of the house was located in western side of the house and a small bath room cum toilet, outside the house. The northern end of the house area was used as a kitchen and noticed cooking utensils near the oven and on the western side wall, only one window was present. An old laundry basket was seen in the southern end of the house. A male dead body named Chinnakaman, the husband of the complainant was found in a pool of blood. The body was found in northwest direction with head on northern side and face facing the roof. He worn lungi with shirt and the face was covered with blood stains. Blood spurt found around the head region.

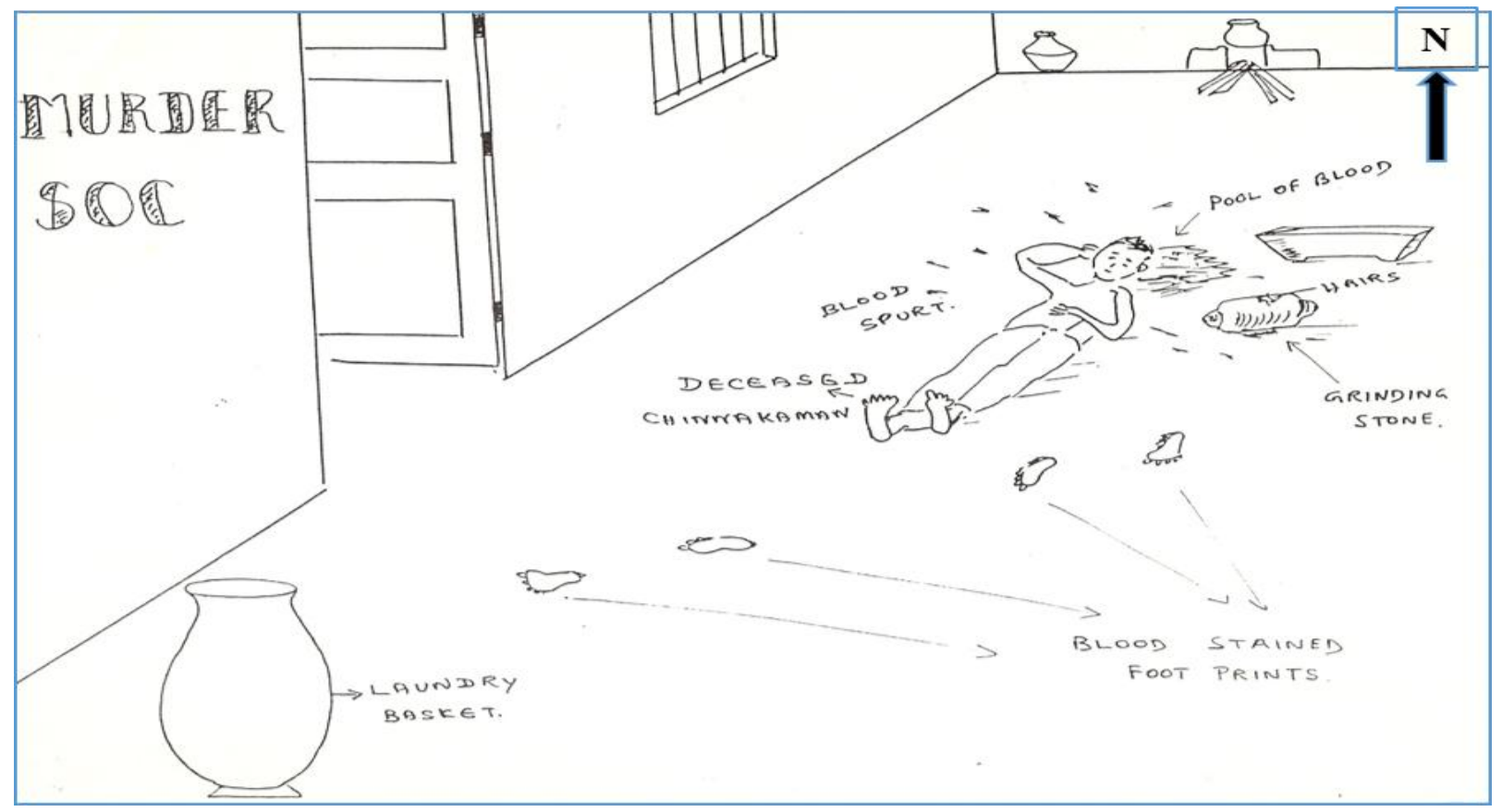

Fig-1: Crime scene sketch showing skit marks and associated evidence

Around 2 feet from the head, TN noticed a grinding stone, generally used those days for grinding chillies, turmeric, coriander etc to make masala paste for the preparation of curry. Before electric blenders, people used a rolling stone over thick flat granite slab for grinding spices manually. On examination of the grinding stone, hair pieces were found on the rolling stone with blood stains. Interestingly $\mathrm{TN}$ noticed blood stained footprints based gait pattern originated from the dead body ended near the door. The crime scene was searched for the presence of any fingerprints and 2 fingerprints were lifted and tallied with the complainant, who used to handle these articles during her routine work in the house. Usually it is Considered inmate fingerprint, since handled by the inmates regularly and hence ignored by the investigators.
The only evidence found at this scene was blood stained gait pattern with foot impressions. Footprints are classified into $2 \mathrm{D}$ and $3 \mathrm{D}$ footprints, the 2D footprints are found in hard surfaces while 3Ds are in soft surfaces and both types can be used to estimate stature [12], gender [13] and body weight [14]. Also footprint shows individual characteristics for person identification and is population specific $[15,16]$. In the present crime scene, 2D footprint based gait pattern found near the dead body, the only linking evidence to identify the murderer.

\section{RESULT AND DISCUSSION}

The footprints were appeared small in size and most probably from the female and not male prints. Earlier enquiry from the complainant revealed that she 
T. Nataraja Moorthy\& M. Baskaran., Sch Int J Law Crime Justice, Mar, 2021; 4(3): 166-169

did not enter into the house. She said that when she opened the door from outside, she found her husband dead inside the house and without entry, proceeded to police station and lodged complaint over the death of her husband. Based on the enquiry from the neighbours, and size of footprints, the author examined the feet of the deceased wife, and collected swab from the feet and conducted spot test in the crime scene itself which showed positive for the presence of blood. As the author TN was a declared footprint expert, he has collected footprints of the wife and gait pattern, following the standard procedure [17-19]. The result of comparison analysis showed that the footprints and gait pattern from the murder scene and the wife of the deceased are one and the same. The blood stained footprints and gait pattern were left by the wife, the complainant. It is a clear indication of the involvement of the wife to murder her husband. The hair pieces and blood stains collected from the grinding stone and deceased were sent to Forensic Science Laboratory for analysis and laboratory result confirmed the crime scene findings. On interrogation, the wife of the deceased had confessed her crime commission. She that her husband was an alcoholic and used to pick up quarrel with his wife frequently and did not look after the family nor family expenses. On the day of incident, under the influence of alcohol, he picked up quarrel and started beating his wife, and unable to tolerate his atrocity, the wife had picked up the grinding stone found nearby and murdered him. She walked on the blood, leaving blood stained footprints and gait pattern. She came out of the house, and washed her feet and hands in the washroom, located outside the house and then came to the police station and lodged the complaint, as if somebody murdered her husband. The author had prepared a crime scene report and sent to the police officer for the onward transmission to the court. As requisitioned by the court, then forensic crime scene investigator, current Professor of Forensic Sciences had attended the Session Court and presented his testimony in the court. The Honourable Judge accepted value of footprint and gait pattern evidence and at length the case ended with conviction. As a former crime scene investigator, the author had already published his crime scene works involved footprint evidence in cases like property crime, suspicious death etc. [20, 21]. Researchers have confirmed that footprint based gait pattern analysis technique can be utilized with confidence in adult populations for both clinical and research purposes [23].

\section{CONCLUSION}

The present forensic podiatry crime scene report on footprint based gait pattern, as accepted in the session court, in the absence of any evidence, made it clear that even though the perpetrator used gloves and mask during crime operation to hide the evidence, but still unconsciously leave their foot impressions and gait pattern in the crime scenes that identify the offender scientifically. Thus the investigators need to update their knowledge on gait pattern evidence collection and analysis so as to arrive a definite conclusion in any disputed crime scenes during the investigation process. Otherwise, investigators simply ignored the evidence and lost the chance of identification in the criminal justice system [22].

\section{REFERENCES}

1. Henry, C. Lee., Elaine, M.P. (2013). Forensic evidence and crime scene investigation. Journal of Forensic Investigation, 1(2):1-5.

2. James, W.O. (1969). The evaluation of physical evidence in criminalistics: Subjective or objective process? The Journal of Criminal Law, Criminology and Police Science, 60(1): 97-101.

3. Nataraja, Moorthy, T., Ahmad, M.M., Boominathan, N., Raman, N. (2014). Stature estimation from footprint measurements in Indian Tamils by regression analysis. Egyptian Journal of Forensic Sciences, 4: 7-16.

4. Nataraja, Moorthy, T., Povaneswari, G. (2018). Inheritance of fingerprint pattern among Indian family members. International Journal of Medical Toxicology \& Legal Medicine, 21(3):119-121.

5. Nataraja, Moorthy, T., Nor Amalina, A.H, G. (2018). Study on hair morphology to discriminate the dominant ethnic groups in Malaysian Borneo. International Journal of Medical Toxicology \& Legal Medicine, 21(3):205-207.

6. Nataraja Moorthy, T., Khaja, M. (2019). Robber's handwritings on the wall solved the mystery: A rare case report. Journal of South India MedicoLegal Association, 11(2):119-123.

7. Nataraja, Moorthy, T., Josua, E. (2018). Forensic subsoil profile investigation in Taman Rakyat Recreation Park, Klangor, Selangor, Malaysia. International Journal of Medical Toxicology \& Legal Medicine, 21(3):171-174.

8. Laurent, L., Kyra, L., Krist, D.W. (2020). Interpol review of fibres and textiles 2016-2019. Forensic Science International, 2: 481-488.

9. Nataraja, Moorthy, T., Keethaambigai, N. (2016). The study on enhancement of handwritings on selected charred documents using Video Spectral Comparator (VSC). Arab Journal of Forensic Sciences and Forensic Medicine, 1(4): 282-286.

10. Nataraja, Moorthy, T., Hasyir, F. (2018). A preliminary study on charring rate of selected Malaysian timbers for fire investigation. International Journal of Medical Toxicology \& Legal Medicine, 21(3):130-132.

11. Nataraja, Moorthy, T., Mohd Hadzri, Y. (2010). The study on the microscopic characteristics in heat seals in plastic bags and its stability for application during forensic comparison. Journal of Indian Academy of Forensic Sciences, 42(1\&2):19-26. 
T. Nataraja Moorthy\& M. Baskaran., Sch Int J Law Crime Justice, Mar, 2021; 4(3): 166-169

12. Nataraja, Moorthy, T., Hairunnisa, M.A.K. (2014) Stature estimation from the anthropometric measurements of footprint in Iban Ethnics of East Malaysia by regression analysis. Journal of Forensic Science and Criminology, 1(5): 1-7.

13. Nataraja Moorthy, T., Hairunnisa, M.A.K. (2018). Gender variation from footprint toes among Ibans, an indigenous ethnic group in Malaysian Borneo. International Journal of Medical Toxicology \& Legal Medicine, 21(3): 208-211.

14. Nataraja, Moorthy, T., Hairunnisa, M.A.K. (2016). Determination of body weight from footprint and foot outline breadth anthropometry among Melanau ethnics of Borneo Island, east Malaysia for forensic investigation. Malaysian Applied Biology Journal, 45(2):139-144.

15. NatarajaMoorthy, T., Siti Fatimah, S. (2015). Individualizing characteristics of footprints in Malaysian Malays for person identification in forensic perspective. Egyptian Journal of Forensic Sciences, 5:13-22.

16. Nataraja, Moorthy, T., Teh Yoong, M. (2018). Individualizing characteristics of footprints in Malaysian Chinese for person identification in forensic perspective. Journal of South India Medico-Legal Association, 10(2):59-69.

17. Nataraja, Moorthy, T., Rina Haryani, O.B. (2007).
Study on the extent of individuality of the gait pattern of Malay subject. The Malaysian journal of Medical Sciences, 14(1): 61.

18. Nataraja, Moorthy, T. (2008). Gait Pattern Analysis in Crime Scene investigation. Tamilnadu Police Journal, 2(3): 61-70.

19. Nataraja Moorthy, T., Sharmila Devi., Eva T.L.Y. (2018). Footprint based gait pattern analysis among Malaysian Indians for person identification in forensic science perspective. Journal of Management \& Science, 16(1): 53-61.

20. Nataraja, Moorthy, T. (2019). Footprint evidence solved the mystery in a suspicious death: A rare case report. Peer Reviewed Journal of Forensic \& Genetic Science, 3(2):183-185.

21. Nataraja, Moorthy, T. (2019). Malicious Destruction of Plantation (MDOP) and 3D Footprint Identified the Perpetrator: A Rare Case Report(2019). Forensic Science \& Addiction Research, 4(3): 1-3.

22. Nataraja, Moorthy, T. (2017). Neglected Physical Evidence during Crime Scene Investigation. Forensic Science \& Addiction Research, 1(2): 1-2.

23. Wilkinson, M.J., Menz, H.B. (1997). Measurement of gait parameters from footprints: a reliable study. The Foot, 7: 19-23. 